\title{
Impact of associated injuries in the Floating knee: A retrospective study
} Ulfin Rethnam*1, Rajam S Yesupalan² and Rajagopalan Nair ${ }^{3}$

Address: ${ }^{1}$ Department of Orthopaedics, Glan Clwyd Hospital, Bodelwyddan, UK, ${ }^{2}$ Department of Accident \& Emergency, Glan Clwyd Hospital, Bodelwyddan, UK and ${ }^{3}$ Department of Orthopaedics, St John's Medical College, Bangalore, India

Email: Ulfin Rethnam* - ulfinr@yahoo.com; Rajam S Yesupalan - ajeesh2000@yahoo.co.uk; Rajagopalan Nair - remraj@bgl.vsnl.net.in

* Corresponding author

Published: 14 January 2009

BMC Musculoskeletal Disorders 2009, 10:7 doi:10.1 I86/147/-2474-10-7

Received: 19 February 2008

Accepted: 14 January 2009

This article is available from: http://www.biomedcentral.com/I47/-2474//0/7

(C) 2009 Rethnam et al; licensee BioMed Central Ltd.

This is an Open Access article distributed under the terms of the Creative Commons Attribution License (http://creativecommons.org/licenses/by/2.0), which permits unrestricted use, distribution, and reproduction in any medium, provided the original work is properly cited.

\begin{abstract}
Background: Floating knee injuries are usually associated with other significant injuries. Do these injuries have implications on the management of the floating knee and the final outcome of patients? Our study aims to assess the implications of associated injuries in the management and final outcome of floating knee.

Methods: 29 patients with floating knees were assessed in our institution. A retrospective analysis of medical records and radiographs were done and all associated injuries were identified. The impact of associated injuries on delay in initial surgical management, delay in rehabilitation \& final outcome of the floating knee were assessed.

Results: 38 associated injuries were noted. 7 were associated with ipsilateral knee injuries. Lower limb injuries were most commonly associated with the floating knee. Patients with some associated injuries had a delay in surgical management and others a delay in post-operative rehabilitation. Knee ligament and vascular injuries were associated with poor outcome.

Conclusion: The associated injuries were quite frequent with the floating knee. Some of the associated injuries caused a delay in surgical management and post-operative rehabilitation. In assessment of the final outcome, patients with associated knee and vascular injuries had a poor prognosis. Majority of the patients with associated injuries had a good or excellent outcome.
\end{abstract}

\section{Background}

Floating knee injuries (ipsilateral fractures of the femur and tibia) are always due to high energy trauma. The force required to fracture two of the strongest bones in the body is immense. Not surprisingly, these injuries are associated with other injuries (bony and soft tissue). These patients are usually haemodynamically unstable and need close monitoring and resuscitation during the initial period of following injury.
The need for a thorough secondary survey cannot be overemphasised. The grossly deformed limb that one encounters in the floating knee can act as a major "distracting factor" and it is not unusual to miss other significant injuries. Do these injuries have a bearing on the management on the floating knee? Most studies on the floating knee concentrate on their treatment, with just a mention of the associated injuries. [1-7] 
Our study aims to assess the impact of associated injuries in the management and final outcome of the floating knee.

\section{Methods}

This study was conducted over a 3 year period in a tertiary care teaching hospital after approval of the Hospital Research \& Ethics Committee (St. John's Medical College).

This was a retrospective analysis of associated injuries in patients with floating knee injuries. The study included all patients with surgically treated ipsilateral fractures of the femur and tibia encountered during the study period. Data was collected from the medical records of patients and the bony injuries where confirmed on radiographs taken. The data collected included the type of associated injury, its treatment, delay in surgical management of the floating knee due to associated injuries, delay in rehabilitation and their impact on the final outcome.

After primary survey, resuscitation and splinting of the affected limb, a thorough secondary survey was performed to identify any associated injuries. This involved examining the patient from head to toe looking for any evidence of fractures or other injuries. Relevant radiographs were done for a suspected associated injury. Open fractures were managed according to the departmental protocol (wound toilet, antibiotics and urgent surgical stabilisation of fractures). Once the associated injuries were identified, treatment was planned together with management of the floating knee.

The floating knee injuries encountered were classified according to the Blake and McBryde classification. [8] (Table 1) This classification system included all varieties of floating knee injuries including articular fractures around the knee, fractures of the hip and ankle. This was therefore a comprehensive classification as compared to the other classification systems that exist for the floating knee. $[9,10]$ After resuscitation, the floating knee fractures were managed surgically. The identified associated injuries were treated appropriately under the same anaesthesia. Patients were assessed after clinical and radiological union of the fractures. The end result was assessed by the Karlstrom criteria. (Table 2) [11]

\section{Results}

29 patients with floating knees were included in the study. There were 27 males and 2 females. The mean age was 28 years (Range 18 - 56). Road traffic accidents accounted for 27 patients while 2 patients sustained their injuries after a fall from height. The right side was involved in 19 patients and the left side in 10 patients. There were 21 Type 1 floating knees, 4 Type 2A injuries and 5 Type 2B injuries (Blake and McBryde classification, Table 1). None of the patients had any previous significant medical problems such as cardiovascular or pulmonary disease, previous deep vein thrombosis, pulmonary embolism increasing operative risk or causing delay in initial surgical management.

Most of the floating knee injuries were treated with antegrade intramedullary nailing for both the femur and tibia (20/29 patients). Other modes of treatment included dynamic hip screw fixation, dynamic condylar screw fixation, tibial buttress plate fixation and external fixation. The femoral fracture was stabilised initially followed by the tibial fracture. Surgical stabilisation of associated fractures was performed under the same anaesthesia. Chemical thromboprophylaxis with enoxaparin was started on all patients at time of admission and this was continued post-operatively. The post operative regime was to start knee range of movement exercises and mobilisation partial weight bearing using crutches on the second post operative day by physiotherapists. Continuous passive motion was used daily for knee mobilisation till satisfactory knee movements were achieved. After union of the fractures, assessment by the Karlstrom criteria revealed the following results; excellent -15 , good - 10, acceptable 1 , poor -3 . The mean follow up was 24.2 months (Range $16-28$ months).

38 associated injuries were noted in the 29 patients. Only 3 of the 29 patients had isolated floating knee injuries. The associated injuries ranged from head injury to metatarsal fractures. (Table 3 )

Table I: Blake and McBryde classification for Floating Knee injuries

\begin{tabular}{ll}
\hline Type I - True Floating Knee & The knee joint is isolated completely and not involved, with either shaft fractured \\
\hline Type 2 - Variant Floating knee & Involves one or more joints with either shaft fractured. \\
\hline Type 2A & The knee joint alone is involved \\
\hline Type 2B & Involves the hip or ankle joints \\
\hline
\end{tabular}


Table 2: Karlstrom criteria for functional assessment after management of floating knee injuries

\begin{tabular}{|c|c|c|c|c|}
\hline Criterion & Excellent & Good & Acceptable & Poor \\
\hline $\begin{array}{l}\text { Symptoms from thigh or } \\
\text { leg }\end{array}$ & None & Intermittent slight symptoms & $\begin{array}{l}\text { More severe symptom impairing } \\
\text { function }\end{array}$ & $\begin{array}{l}\text { Considerable functional } \\
\text { impairment: pain at rest }\end{array}$ \\
\hline $\begin{array}{l}\text { Symptoms from knee or } \\
\text { ankle joint }\end{array}$ & None & Same as above & Same as above & Same as above \\
\hline Walking ability & Unimpaired & Same as above & Walking distance restricted & $\begin{array}{l}\text { Uses cane, crutch or other } \\
\text { support }\end{array}$ \\
\hline Work and sports & Same as before & $\begin{array}{l}\text { Given up sport; work same as } \\
\text { before }\end{array}$ & Change to less strenuous work & Permanent disability \\
\hline $\begin{array}{l}\text { Angulation, rotational } \\
\text { deformity or both }\end{array}$ & 0 & $<10$ degrees & $10-20$ degrees & $>20$ degrees \\
\hline Shortening & 0 & $<$ I centimetre & I - 3 centimetres & $>3$ centimetres \\
\hline Restricted joint mobility & 0 & $\begin{array}{l}<10 \text { degrees at ankle; }<20 \\
\text { degrees at hip, knee or both }\end{array}$ & $\begin{array}{l}10-20 \text { degrees at ankle; } 20-40 \\
\text { degrees at hip, knee or both }\end{array}$ & $\begin{array}{l}>20 \text { degrees at ankle; }>40 \\
\text { degrees at hip, knee or both }\end{array}$ \\
\hline
\end{tabular}

\section{Head and neck injuries}

3 patients sustained head injuries for which a CT scan of the brain was done. The initial assessment included a neurological assessment, pupil size and the Glasgow Coma Scale (GCS). A clinical and radiological assessment of the neck was done to look for cervical spine injuries. None of these patients had intracranial bleeds or haematomas that needed intervention by the neurosurgeons. All of these patients were diagnosed to have cerebral concussion and had supplemental oxygen till the post operative period. Surgical fixation of the fractures was done once they were neurologically stable with a GCS of 15. 2 head injured patients had contralateral tibia \& femur fractures respectively. (Table 4) There was a mean delay in surgical management of the floating knee due to head injury of 2 days (Range 1-3 days). There was no delay in rehabilitation due to the head injury and all the three patients had an excellent final outcome when assessed using the Karlstrom criteria. (Table 4) None of the patients in the study sustained neck injuries.

\section{Fat embolism}

3 patients were diagnosed to have fat embolism within 48 hours of admission. (Table 4) The diagnosis was made if the patients had pyrexia, tachycardia, tachypnoea and had altered sensorium after admission. Blood gases confirmed hypoxia in these patients who were managed in the intensive care unit with mechanical ventilation. Surgical management of the fractures were delayed by a mean 9 days (Range 8-11 days)in these patients. Fat embolism did not cause any delay in rehabilitation of the patients after surgery. 2 patients had excellent results and one patient a good result on assessment of the final outcome.

\section{Chest \& abdomen injuries}

2 patients were clinically and radiologically diagnosed to have haemopneumothorax that needed tube thoracostomy insertion. (Table 4) The chest drain was inserted in the Accident \& Emergency and removed when the haemopnemothorax had radiologically reduced and the patient was symptomatically better. 1 patient had multiple rib fractures which delayed the post operative rehabilitation by 2 weeks. The chest injuries did not seem to have an

Table 3: Associated injuries with Floating knee and their management

\begin{tabular}{|c|c|c|}
\hline Associated injury & Patients & Intervention \\
\hline Patellar fractures & 3 & Open reduction internal fixation \\
\hline Knee ligament injuries & 4 & Ligament repair, medial meniscectomy \\
\hline Clavicle fractures & 4 & Conservative \\
\hline Femoral fractures (opposite) & 3 & Intramedullary nailing \\
\hline Femoral artery injury & 1 & Femoro-popliteal bypass graft \\
\hline Humeral shaft fractures & 4 & Open reduction internal fixation \\
\hline Head injury & 3 & Conservative \\
\hline Rib fractures & 1 & Conservative \\
\hline Haemo-pneumothorax & 2 & Chest drain insertion \\
\hline Forearm bones fractures & 1 & Open reduction internal fixation \\
\hline Contralateral tibial fractures & 4 & Intramedullary nailing \\
\hline Metatarsal fractures & 4 & Conservative \\
\hline Fat embolism & 3 & Mechanical ventilation \\
\hline Radial nerve palsy & I & Conservative \\
\hline
\end{tabular}


Table 4: Implications of associated injuries in the floating knee

\begin{tabular}{|c|c|c|c|c|c|c|}
\hline Patient & Associated injury & Injury Severity Score & $\begin{array}{l}\text { Delay in primary } \\
\text { surgery }\end{array}$ & $\begin{array}{l}\text { Surgical duration } \\
\text { (Min) }\end{array}$ & $\begin{array}{l}\text { Delay in } \\
\text { rehabilitation }\end{array}$ & $\begin{array}{l}\text { Final outcome } \\
\text { (Karlstrom) }\end{array}$ \\
\hline I & None & 9 & 0 & 140 & Nil & Excellent \\
\hline 2 & Cerebral concussion & 18 & 2 days & 120 & $\mathrm{Nil}$ & Excellent \\
\hline 3 & $\begin{array}{l}\text { Clavicle, Fat } \\
\text { embolism }\end{array}$ & 9 & 8 days & 110 & Nil & Excellent \\
\hline 4 & Patella & 9 & 0 & 180 & 4 weeks & Good \\
\hline 5 & Contralateral femur & 9 & 0 & 200 & 2 weeks & Good \\
\hline 6 & $\begin{array}{l}\text { Anterior Cruciate } \\
\text { tear }\end{array}$ & 9 & 0 & 210 & 4 weeks & Poor \\
\hline 7 & $\begin{array}{l}\text { Clavicle, Humerus, } \\
\text { Forearm, Metatarsal }\end{array}$ & 9 & 0 & 210 & 4 weeks & Good \\
\hline 8 & $\begin{array}{l}\text { Medial meniscus } \\
\text { injury }\end{array}$ & 9 & 0 & 180 & Nil & Good \\
\hline 9 & None & 9 & 0 & 120 & Nil & Excellent \\
\hline 10 & Contralateral tibia & 9 & 0 & 150 & 2 weeks & Excellent \\
\hline II & Humerus & 9 & 0 & 170 & 4 weeks & Excellent \\
\hline 12 & Fat embolism & 9 & II days & 110 & Nil & Excellent \\
\hline 13 & $\begin{array}{l}\text { Clavicle, Haemo- } \\
\text { pneumothorax }\end{array}$ & 25 & 0 & 130 & Nil & Excellent \\
\hline 14 & Metatarsal & 9 & 0 & 120 & Nil & Excellent \\
\hline 15 & $\begin{array}{l}\text { Humerus, Radial } \\
\text { nerve }\end{array}$ & 9 & 0 & 180 & 4 weeks & Good \\
\hline 16 & $\begin{array}{l}\text { Contralateral tibia, } \\
\text { Fat embolism }\end{array}$ & 9 & 9 days & 160 & 2 weeks & Good \\
\hline 17 & Contralateral femur & 9 & 0 & 170 & 2 weeks & Good \\
\hline 18 & $\begin{array}{l}\text { Posterior Cruciate } \\
\text { tear }\end{array}$ & 9 & 0 & 200 & 4 weeks & Poor \\
\hline 19 & $\begin{array}{l}\text { Clavicle, Rib, } \\
\text { Haemo- } \\
\text { pneumothorax }\end{array}$ & 25 & 0 & 120 & 2 weeks & Excellent \\
\hline 20 & Patella, Metatarsal & 9 & 0 & 160 & 4 weeks & Good \\
\hline 21 & None & 9 & 0 & 110 & Nil & Excellent \\
\hline 22 & $\begin{array}{l}\text { Contralateral tibia, } \\
\text { Cerebral concussion }\end{array}$ & 18 & 3 & 170 & 2 weeks & Excellent \\
\hline 23 & Humerus & 9 & 0 & 180 & 3 weeks & Excellent \\
\hline 24 & $\begin{array}{l}\text { Femoral artery } \\
\text { injury }\end{array}$ & 9 & 0 & 260 & 3 weeks & Poor \\
\hline 25 & Contralateral tibia & 9 & 0 & 180 & 2 weeks & Good \\
\hline 26 & $\begin{array}{l}\text { Anterior Cruciate } \\
\text { tear }\end{array}$ & 9 & 0 & 200 & 4 weeks & Acceptable \\
\hline 27 & Metatarsal & 9 & 0 & 130 & Nil & Excellent \\
\hline 28 & $\begin{array}{l}\text { Contralateral femur, } \\
\text { concussion }\end{array}$ & 18 & 1 & 180 & 2 weeks & Excellent \\
\hline 29 & Patella & 9 & 0 & 160 & 4 weeks & Good \\
\hline
\end{tabular}

impact on the final outcome as both these patients had excellent results. All patients had clinical evaluation of the abdomen on arrival to the hospital and none had signs of any intra-abdominal injuries.

\section{Associated upper limb injuries}

10 injuries were encountered in 7 patients. Most of the injuries were fractures with 1 patient sustaining a radial nerve injury. The clavicle and humerus was the most common upper limb bones fractured. The clavicle fractures were managed conservatively while all humerus fractures were surgically fixed (Dynamic compression plating). In the patient with radial nerve palsy, the radial nerve was explored during fixation of the humerus and found to be contused therefore managed conservatively. The clavicle fractures did not have an impact on time for rehabilitation or the final outcome as all these patients had either excellent or good results. (Table 4) The average surgical duration was $185+/-17.3$ minutes (Range $170-210$ ) when upper limb fractures were fixed along with the floating knee as compared to $121+/-9.9$ minutes (Range 110 $140)$ with fixation of isolated floating knee. There was a mean delay of 3.75 weeks (Range 3 - 4 weeks) for post operative rehabilitation with upper limb injuries that were surgically fixed (Humerus and forearm). Upper limb injuries did not have a negative impact on the final out- 
come as all patients had an excellent to good result. (Table 4)

\section{Associated lower limb injuries}

16 patients with 18 lower limb injuries were encountered. Most injuries were fractures. (Table 4) Contralateral tibia and metatarsal fractures were the most common associated lower limb fracture (4 patients) with contralateral femur and ipsilateral patella fractures the next common fractures (3 patients). The average surgical duration was $184+/-27.4$ minutes (Range 150 - 260) when lower limb injuries were fixed along with the floating knee as compared to $121+/-9.9$ minutes (Range $110-140$ ) with fixation of isolated floating knee. The mean delay in rehabilitation was 2.6 weeks (Range 2 - 4 weeks) with lower limb injuries. This delay was more in patients with ipsilateral knee injuries (patella fractures, crucuaite ligament injuries) as compared to foot fractures or contralateral lower limb fractures (tibia and femur). Contralateral femur or tibia fractures did not have a negative impact in the final outcome. (Table 4)

1 patient had a femoral artery injury which was suspected clinically and evaluated by a femoral angiogram. This revealed an intimal injury of the superficial femoral artery that needed a femoro-popliteal bypass graft which was performed by the vascular surgeons after surgical stabilisation of the fractures. Surgical stabilisation of the fractures was done initially to avoid placing stress on the vascular bypass graft during reduction of the fractures. The rehabilitation of this patient was delayed by 3 weeks and the final outcome assessed by the Karlstrom criteria was poor.

\section{Associated ipsilateral knee injuries}

7 patients had ipsilateral knee injuries ( 3 patellar fractures, 2 anterior cruciate ligament tears, 1 posterior cruciate ligament tear and a bucket handle medial meniscal tear). Knee ligament injuries were diagnosed by clinical assessment by the surgeon after surgical stabilisation of the fractures. Lachman's test and posterior drawer's test were used to clinically assess the anterior and posterior cruciate ligaments respectively. If a knee ligament injury was suspected, a diagnostic arthroscopy was performed under the same anaesthesia and primary ligament repair done. The patellar fracture surgical stabilisation was done under the same anaesthesia. The mean delay in rehabilitation was 4 weeks in patients with ipsilateral knee injuries as these patients were placed in a brace post operatively. There were 2 poor results and an acceptable result in patients with knee ligament injuries. (Table 4)

The complications encountered were knee stiffness in 4 patients, delayed union of tibia in 2 patients and superficial infection in 2 patients. The secondary procedures were manipulation under anaesthesia for knee stiffness, dyna- misation in one patient with delayed union. Patients with delayed union needed either dynamisation of the tibial nail or removal of external fixator and functional bracing of the fracture. These fractures went on to unite following these interventions. The superficial infections were related to pin sites of the external fixators which were managed by pin site care and antibiotics. The infection settled with this management.

\section{Discussion}

Floating knee injuries are caused by high energy trauma which can have an effect on other parts of the body. These patients sustain significant and occasionally life threatening associated injuries. Many studies in the literature mention associated injuries like head, chest, abdominal injuries and injuries to other extremities. [12] Injuries to the head, chest and abdomen can be life threatening. The reported mortality rate ranged from $5-15 \%$ reflecting the seriousness of associated injuries in the floating knee. [12] There is a higher incidence of neurovascular and soft tissue injury in this injury. Surgical stabilisation of both fractures in the floating knee has been found to have the best outcome results. [5]

As these injuries occur consequent to high velocity trauma, the associated injuries (head injury, chest, vascular injury and other fractures have a significant role in surgical decision making with regards to timing of surgery and sequence of surgery. Any associated medical co-morbidities can worsen the already compromised physiologic reserve especially in the elderly.

Poole GV et al (13) in a comparison study on lower extremity fracture fixation in the head injured patient found that surgical stabilisation of fractures within 24 hours of injury reduced the risk of pulmonary complications (fat embolism, pneumonia and adult respiratory distress syndrome. [13] Cerebral injury has been found to be associated with high risk of pulmonary complications. $[14,15]$ A delay in fracture fixation did not protect the injured brain. There is no data in the literature that the injured brain is at risk for further injury during the surgical procedure provided the patient is not exposed to hypotension and hypoxia. In our study patients with head injury had CT scan to the brain to rule out an intracranial bleed or haematoma. There was a delay in surgery for these patients as they had a fluctuating Glasgow Coma scale and once their GCS had become normal we stabilised the fractures. All patients with fluctuating conscious levels need a CT scan of the brain. If an intracranial haematoma or bleed is diagnosed these patients should be referred to the neurosurgery unit for further management.

Vascular assessment of the affected limb is of utmost importance in detecting any vascular injury. Cakir $\mathrm{O}$ et al 
[16] in their study on the treatment of vascular injuries associated with limb fractures recommended careful assessment of the peripheral pulses by palpation or hand held Doppler. If an arterial injury was suspected, a preoperative angiogram was done if there was no critical ischaemia to the limb. There has been a well established debate over the sequence of surgical vascular repair and bone stabilisation. [16-20] McHenry et al in their study found no iatrogenic disruption of the vascular repair when bone stabilisation followed vascular repair. [21] The general consensus is that bone stabilisation should precede vascular repair in unstable fractures while in stable fractures vascular repair should be done first to avoid prolonged ischaemia to the limb. In our study there was one patient with a superficial femoral artery injury which was diagnosed by absent distal pulses using a hand held Doppler. This patient was referred to the vascular surgeons who performed an on-table angiogram followed by a femoro-popliteal bypass graft. If a vascular injury is suspected, referral to the vascular surgeons is the norm and assessment of the affected limb by an angiogram is performed. Repair of the vascular injury is best done after surgical stabilisation of the fractures as the floating knee is an unstable injury and manipulation of the fracture after repair of a vessel can put stress on the repair leading to failure of the repair. In our study the patient with vascular injury had a delay in rehabilitation and a poor final outcome. Vascular injuries associated with the floating knee are a poor prognostic indicator and should be assessed and managed with care.

Many studies have documented that early surgical stabilisation of fractures were associated with significant reduction in pulmonary complications such as fat embolism, pneumonia and Adult Respiratory Distress Syndrome. $[22,23]$

When encountered in the elderly, the diminished physiologic reserve and pre-existing co-morbid conditions may contribute to higher morbidity and mortality following a floating knee injury. The principle here is to manage the patient's co-morbidities (cardio-respiratory, renal etc) till the patient is fit to undergo surgery. Surgery after this has shown to improve the patient's final outcome. $[24,25]$

If significant abdominal injuries are detected, these take priority over surgical stabilisation of the fractures. Detection of abdominal injuries should be by clinical assessment and ultrasonography. If there was a suspicion of intra-abdominal injury, an urgent CT scan is indicated. In our study, we did not have any patients with significant abdominal trauma, intracranial haematoma or bleed.

Associated ipsilateral knee ligament injuries are common in the floating knee and this is documented in the litera- ture. $[6,12,26]$ These can be a diagnostic enigma in the floating knee due to difficulty in clinical assessment of the knee in the presence of fractures on both sides of the knee. These injuries are easily missed due to the "distracting" nature of a floating knee injury. Appropriate management of the knee ligament injury is essential for a good outcome after treatment of the floating knee. Szalay MJ et al in their study of 34 floating knees found detectable ligament laxity in 53\%. [26] The Lachmann test is almost $100 \%$ diagnostic of anterior cruciate ligament tear when performed under anaesthesia. $[20,27]$ Moore et al found that when knee ligament injuries were repaired a better range of motion was achieved in femoral fractures. They recommended surgical stabilisation of the fracture, stress testing of knee ligaments, acute arthroscopy and ligament repair if knee ligament tear was suspected. [20] Other studies have favoured acute repair of knee ligaments. [28]

In all patients we assessed the knee ligaments after surgical stabilisation of both the femoral and tibial fractures under the same anaesthesia. If instability was detected we proceeded to perform a diagnostic arthroscopy and repaired the ligaments. This avoided the need for an MRI assessment of the knee and further anaesthetic exposure for ligament reconstruction. We did not perform an MRI evaluation of the knees as assessment (clinical and arthroscopic) to detect knee ligament injuries was satisfactory. Although an MRI is the gold standard investigation for evaluating knee ligament injuries, with a floating knee performing an MRI prior to surgical stabilisation of the fractures would cause problems in the patient who may be haemodynamically unstable. After surgical stabilisation of the fractures there may be interference artefacts from the metal work, preventing proper visualisation of the knee ligaments. We feel that a clinical assessment under anaesthesia followed by a diagnostic arthroscopy is the best method of assessment of ligament injuries in these patients.

Most studies discuss the treatment options of floating knee in great depth but not much is mentioned about the associated injuries. The impact of associated injuries on the treatment of floating knee has never been discussed. We have tried to assess the importance of associated injuries in the floating knee by this study. Although the incidence of associated injuries were high (38 in 29 patients), assessing the final outcome, in our study only four patients $(4 / 29)$ had less than a good outcome (3 poor and 1 acceptable). These were three patients with associated knee ligament injuries and one patient with a vascular injury. Some of the associated injuries with the floating knee had an impact in the management of the patient with regards to surgical delay and delay in rehabilitation. Patients who sustained head injuries and fat embolism had a delay in surgical treatment as compared to other 
associated injuries. This delay in surgical treatment had no impact on the final outcome of these patients. Patients with ipsilateral knee injuries (Patella fractures, cruciate ligament injuries) and upper limb fractures (humerus \& forearm) tended to have an increased delay in rehabilitation as compared to patients with contralateral lower limb fractures (tibia, femur) and those with chest injuries (rib fractures, haemo-pnemothorax).

The limitation of our study is the small sample size. Even in this small sample the total number of associated injuries was high (38 in 29 patients). Despite this high incidence of associated injuries, the number of injuries for each floating knee was small and this is another limitation of our study as recommendations for treatment are on this small sample.

\section{We recommend}

1. Thorough secondary survey to detect associated injuries such as chest, abdomen, vascular injury, head injury and other fractures.

2. Life threatening injuries (Haemothorax, pneumothorax, intraabdominal injury, intracranial bleed or haematoma) to be managed as a priority.

3. Early stabilisation of the fractures by 2 teams to reduce the surgical duration.

4. Knee assessment to detect ligament injuries after stabilisation of the fractures.

5. Management of associated fractures under the same anaesthesia.

6. Post-operative monitoring to detect development of fat embolism.

7. Early institution of aggressive physiotherapy to regain good function.

\section{Conclusion}

There is a high incidence of associated injuries with the floating knee. Most patients with associated injuries with the floating knee had an excellent or good outcome. Despite this, associated injuries are important with regards to planning of management. Once other injuries have been identified, a plan has to be made on the type of management. Adhering to a management protocol should give a better final outcome in patients with this severe injury.

\section{Competing interests}

The authors declare that they have no competing interests.

\section{Authors' contributions}

UR was involved in conducting the study, collecting patient details, reviewing the literature, drafting the manuscript and proof read the final manuscript. RSY was involved in reviewing the literature and proof read the manuscript. $\mathrm{RN}$ is the senior author who supervised the study and was responsible for final proof reading of the article.

\section{Acknowledgements}

Funding was neither sought nor obtained.

\section{References}

I. Dwyer AJ, Paul R, Mam MK, Kumar A, Gosselin RA: Floating knee injuries: long-term results of four treatment methods. Int Orthop 2005, 29(5):3 14-8.

2. Fraser RD, Hunter GA, Wadell JP: Ipsilateral fracture of the femur and tibia. J Bone and Joint surgery 1978, 60B(4):5I0-515.

3. Hee HT, Wong HP, Low YP, Myers L: Predictors of outcome of floating knee injuries in adults: 89 patients followed for 2-12 years. Acta Orthop Scand 200I, 72(4):385-94.

4. Hojer H, Gillquist J, Liljedahl SO: Combined fractures of the femoral and tibial shafts in the same limb. Injury 1977, 8(3):206-I2.

5. Lundy DW, Johnson KD: "Floating knee" injuries: ipsilateral fractures of the femur and tibia. J Am Acad Orthop Surg 200I, 9(4):238-45.

6. Paul GR, Sawka MW, Whitelaw GP: Fractures of the ipsilateral femur and tibia: emphasis on intra-articular and soft tissue injury. J Orthop Trauma 1990, 4(3):309-14.

7. Veith RG, Winquist RA, Hansen ST Jr: Ipsilateral fractures of the femur and tibia. A report of fifty-seven consecutive cases. J Bone Joint Surg Am 1984, 66(7):991- 1002.

8. Blake R, McBryde A Jr: The floating knee: Ipsilateral fracture of the tibia and femur. South Med J I 975, 68(I): I3-6.

9. Fraser RD, Hunter GA, Wadell JP: Ipsilateral fracture of the femur and tibia. J Bone Joint Surg $\mathrm{Br}$ 1978, 60-B(4):5।0-5I5.

10. Letts $M$, Vincent N, Gouw G: The "floating knee" in children. J Bone Joint Surg Br 1986, 68(3):442-6.

II. Goran K, Olerud S: Ipsilateral fracture of the femur and tibia. J Bone and Joint surgery Am 1977, 59(2):240-243.

12. van Raay J], Raaymakers EL, Dupree HW: Knee ligament injuries combined with ipsilateral tibial and femoral diaphyseal fractures: the "floating knee". Arch Orthop Trauma Surg 1991, I I 0(2):75-7.

13. Poole GV, Miller JD, Agnew SG, Griswold JA: Lower extremity fracture fixation in head-injured patients. J Trauma 1992, 32(5):654-9.

14. Demling R, Riessen R: Pulmonary dysfunction after cerebral injury. Crit Care Med 1990, I 8(7):768-74.

15. Helling TS, Evans LL, Fowler DL, Hays LV, Kennedy FR: Infectious complications in patients with severe head injury. I Trauma 1988, 28(II): 1575-7.

16. Cakir O, Subasi M, Erdem K, Eren N: Treatment of vascular injuries associated with limb fractures. Ann R Coll Surg Engl 2005, 87(5):348-52.

17. Ashworth EM, Dalsing MC, Glover JL, Reilly MK: Lower extremity vascular trauma: a comprehensive, aggressive approach. J Trauma 1988, 28(3):329-36.

18. Bishara RA, Pasch AR, Lim LT, Meyer JP, Schuler JJ, Hall RF Jr, Flanigan $D P$ : Improved results in the treatment of civilian vascular injuries associated with fractures and dislocations. J Vasc Surg 1986, 3(5):707-I I.

19. Karavias D, Korovessis P, Filos KS, Siamplis D, Petrocheilos J, Androulakis J: Major vascular lesions associated with orthopaedic injuries. J Orthop Trauma 1992, 6(2): 180-5.

20. Moore TM, Patzakis MJ, Harvey JP Jr: Ipsilateral diaphyseal femur fractures and knee ligament injuries. Clin Orthop Relat Res 1988:182-9.

21. McHenry TP, Holcomb JB, Aoki N, Lindsey RW: Fractures with major vascular injuries from gunshot wounds: implications of surgical sequence. J Trauma 2002, 53(4):717-21. 
22. Behrman SW, Fabian TC, Kudsk KA, Taylor JC: Improved outcome with femur fractures: early vs. delayed fixation. J Trauma 1990, 30(7):792-7.

23. Riska EB, Myllynen P: Fat embolism in patients with multiple injuries. J Trauma 1982, 22(I I):89|-4.

24. Davenport HT: Preparations for anaesthesia for the aged. In Anaesthesia in the aged patient Edited by: Davenport HT. Blackwell Scientific publications; 1988:183-203.

25. Vowles KDJ: Surgical decision in the aged. In Anaesthesia in the aged patient Edited by: Davenport HT. Blackwell Scientific publications; 1988: 168-182.

26. Szalay MJ, Hosking OR, Annear P: Injury of knee ligament associated with ipsilateral femoral shaft fractures and with ipsilateral femoral and tibial shaft fractures. Injury 1990, $2 I(6): 398-400$.

27. Jonsson $T$, Althoff $B$, Peterson L, Renstrom P: Clinical diagnosis of ruptures of the anterior cruciate ligament: a comparative study of the Lachman test and the anterior drawer sign. Am J Sports Med 1982, 10(2): 100-2.

28. Walling AK, Seradge H, Spiegel PG: Injuries to the knee ligaments with fractures of the femur. J Bone Joint Surg Am 1982, 64(9):1324-7.

\section{Pre-publication history}

The pre-publication history for this paper can be accessed here:

http://www.biomedcentral.com/1471-2474/10/7/prepub
Publish with Bio Med Central and every scientist can read your work free of charge

"BioMed Central will be the most significant development for disseminating the results of biomedical research in our lifetime. "

Sir Paul Nurse, Cancer Research UK

Your research papers will be:

- available free of charge to the entire biomedical community

- peer reviewed and published immediately upon acceptance

- cited in PubMed and archived on PubMed Central

- yours - you keep the copyright 